\title{
The learning organization and the level of consciousness
}

Ricardo Chiva

Purpose: the aim of this paper is to analyze the learning organization, by making a comparison with other types of organizations. This typology is based on the levels of consciousness and relates each type of organization with a level of learning and an organizational structure.

Approach: Conceptual paper that is based on the concept of levels of consciousness.

Findings: The paper proposes that the learning organization requires the highest level of consciousness.

Originality: The paper uses the levels of consciousness in order to compare the learning organization with other type of organizations.

Keywords: The learning organization, levels of consciousness, levels of learning, organizational structure

Acknowledgements: the author would like to thank Universitat Jaume I for the financial support of this research (ref. P1-1B2013-14)

\section{Introduction}

Thought on learning within organizations has traditionally been divided into two main literatures: the organizational learning and the learning organization literatures. The former has focused on the learning process of an organization and the latter on the factors that facilitate this process or the guidelines to becoming a learning organization (Garratt, 1987; Argyris and Schön, 1996; Tsang, 1997; Chiva and Alegre, 2009), which is considered by some as the idea of tomorrow for many organizations (Örtenblad, 2004).

The learning organization literature aims to describe and analyze organizations, and the people in them, that learn constantly (Chiva and Alegre, 2009). Pedler et al. (1991) define a learning organization as an organization that facilitates learning of all its 
members and continuously transforms itself. This literature focuses on the facilitating factors for organizational learning or on the characteristics that define a learning organization; in short, the contextual variables that facilitate learning (Jerez-Gómez et al., 2005). However, this concept is still considered by many as ambiguous and asks for clarity (Ulrich et al., 1993; Burgoyne, 1999; Örtenblad, 2004). In fact, Örtenblad (2004) claims that some of the writers on the learning organization literature seem to advocate vagueness, suggesting that it is a never ending journey or a tentative road map (Watkins and Golembiewski, 1995). Obviously, this makes it difficult to identify learning organizations.

In this line, Örtenblad (2004) determines four aspects to define learning organizations: organizational learning, learning at work, learning climate, and learning structure. Although the description he offers on each of these aspects helps much to decide or verify whether an organization is a learning organization, it is difficult to be specific if we do not compare learning organizations with other type of organizations. In order to do so, this paper proposes to take into account the levels of consciousness (Gebser, 1949; Graves, 1970; Beck and Cowan, 1996; Wilber, 2000), which express the different stages of human or social evolution. According to these authors and their approach, human beings and their social systems, like organizations, advance in stages, evolving by sudden transformations, like a caterpillar that becomes a butterfly. Every stage represents a particular stadium with an increasing maturity, complexity and consciousness level. A level of consciousness represents a stadium in human and social evolution and implies a framework through which we interpret the world.

Recently, several works have related each level of consciousness or stage of human evolution and social systems with a particular type of organization (eg. Cowan and Todorovic, 2000; Cacioppe and Edwards, 2004; Laloux, 2014) or even with a particular human resource management system (Chiva, 2014). This paper claims that the learning organization will be associated to the highest level of consciousness.

When describing each of these seven stages, authors linked them to a particular color (Beck and Cowan, 1996; Wilber, 2000; Laloux, 2014). The seven stages are:

1) Reactive, Survival, foraging, instinctive, ego not fully formed, small bands of family kinships, no chiefs (Beige).

2) Magic (not aware of cause and effect), search for security, tribes, no death consciousness. Elderly people are the authority (Magenta). 
3) Power, domination, impulsiveness; the world is a tough place where only the powerful, or those that the latter protect, satisfy their needs. The boss (or alpha male) has to provoke fear (Red).

4) Order, rules, conformism, morality, bureaucracy, effectiveness. Do the right thing and you will be rewarded (Blue).

5) Achievement, autonomy, competency, empirical and scientific research. Effectiveness substitutes morality and efficiency. Attain one's goals (Orange).

6) Cooperation, tolerance, pluralism, solidarity, social responsibility, culture, values, teamwork, empowerment (Green).

7) Evolutionary, common welfare, compassion, harmony, holism, systemic thinking, self-management, wholeness (Teal).

However, only the last five levels are related to types of organizations, or, in other words, only those last five levels allowed the existence of organizations (Laloux, 2014). Therefore, these five levels will be analyzed and related to a certain climate, organizational structure or configuration (Mintzberg, 1989) and level of organizational learning (Bateson, 1972; Argyris and Schön, 1974, 1978, 1996; Swieringa and Wierdsma, 1992; Visser, 2007; Tosey et al., 2011). As suggested by these authors, every level of learning includes the lower ones; so for instance when in the controlmeritocratic double loop is considered as the highest level of learning, we assume that single loop learning and zero learning happen also daily. Table 1 summarizes the ideas behind each of these levels of consciousness.

Table 1: Organizations, levels of consciousness and organizational learning

\begin{tabular}{|l|l|l|l|}
\hline Organization & $\begin{array}{l}\text { Level of } \\
\text { consciousness }\end{array}$ & $\begin{array}{l}\text { Level of organizational } \\
\text { learning }\end{array}$ & $\begin{array}{l}\text { Organizational } \\
\text { structure }\end{array}$ \\
\hline $\begin{array}{l}\text { The control- } \\
\text { autocratic } \\
\text { organization }\end{array}$ & $\begin{array}{l}\text { Power } \\
\text { domination (Red) }\end{array}$ & Zero learning & Simple \\
\hline $\begin{array}{l}\text { The control- } \\
\text { bureaucratic } \\
\text { organization }\end{array}$ & $\begin{array}{l}\text { Order and rules } \\
\text { (Blue) }\end{array}$ & Single loop learning & Machine \\
\hline $\begin{array}{l}\text { The control- } \\
\text { meritocratic } \\
\text { organization }\end{array}$ & $\begin{array}{l}\text { Achievement and } \\
\text { autonomy } \\
\text { (Orange) }\end{array}$ & Double loop learning & Diversified \\
\hline
\end{tabular}




\begin{tabular}{|l|l|l|l|}
\hline $\begin{array}{l}\text { The commitment } \\
\text { organization }\end{array}$ & $\begin{array}{l}\text { Cooperation and } \\
\text { tolerance (Green) }\end{array}$ & $\begin{array}{l}\text { Deutero learning or } \\
\text { metalearning }\end{array}$ & $\begin{array}{l}\text { Professional and } \\
\text { missionary }\end{array}$ \\
\hline $\begin{array}{l}\text { The learning } \\
\text { organization }\end{array}$ & $\begin{array}{l}\text { Common welfare } \\
\text { and holism (Teal) }\end{array}$ & Triple loop learning & Innovative \\
\hline
\end{tabular}

\section{The control-autocratic organization}

The control-autocratic organization stresses the importance of the continuous exercise of power in interpersonal relationships (Cowan and Todorovic, 2000; Cacioppe and Edwards, 2004; Laloux, 2014). The chief has to demonstrate power and to bend others to his will to stay in position: fear is the glue to the organization. So, predatory and autocratic leaders manage these organizations.

There is normally no much hierarchy or job titles, but a certain division of labour among the members of the organization. Direct supervision is the main coordinating mechanism, and strategic apex is the most important part of the organization. So, it might be related to Mintzberg's simple configuration (1985).

These organizations tend to perceive their environments as hostile and chaotic, reacting to the several stimuli they face. Therefore, these highly reactive and impulsive organizations might be associated to Bateson's (1972) zero learning. Zero learning (Bateson, 1972) entails responding to stimuli but making no changes based on experience or information. This happens because habituation, completed learning or genetically fixed response (Visser, 2003). Zero learning simply involves the receipt of a signal, no subject to correction by trial and error (Bateson, 1972).

\section{The control-bureaucratic organization}

The control-bureaucratic organization is based on a static worldview of simple morals: there is only one right way of doing things. Its aim is efficiency or a better use of resources (less costs, more production), so reaching higher levels of productivity (Cowan and Todorovic, 2000; Cacioppe and Edwards, 2004; Laloux, 2014).

According to Laloux (2014), these organizations brought about two main breakthroughs: organizations can plan for the medium and long term and they can create organizational structures that are stable. Therefore, formal hierarchies and job 
titles become now essential. Besides, planning (thinking) and execution (doing) are separated within the organization.

These organizations are very stable and changes are viewed with suspicion. Only improvements are mostly accepted. Everything seems to be predictable, safe and relatively static. Leaders are paternalistic and aim to control everything, as employees are perceived as lazy and dishonest. In such a way, if one does the right thing, one is rewarded.

There is a high degree of standardization or work process: norms and rules determine everything one should do in the control-bureaucratic organizations. Processes are very important; in order to replicate what it worked. This is why they live in the past. Future is repetition of the past. With it, critical knowledge does not depend upon one person. Minzberg's machine configurations (1985) are strongly related to them.

In terms of learning, due to the importance of efficiency or aiming to do the things right, and avoid questioning the rules; single loop learning might be the most important organizational learning type (Argyris and Schön, 1974, 1978, 1996). In single loop learning people, organizations, or groups modify their actions according to their difference between expected and reached outcomes. It occurs when errors are detected and corrected without modifying a firm's existing policies, goals or assumptions. In other words, it tries to improve any rule, process or action, when errors or mistakes happen, without questioning its underlying assumptions.

\section{The control-meritocratic organization}

Laloux (2014) considers that in this level of consciousness there is no absolute right and wrong, though plainly there are some things that work better than others. Authority has not always the right answer, so there is an increasing dose of skepticism. On the other hand, it is not only about if one is doing the things right, but if one is doing the right things. Effectiveness replaces efficiency. Therefore achieving the right goals becomes an essential issue (Cowan and Todorovic, 2000; Cacioppe and Edwards, 2004).

Consequently, double loop learning (Argyris and Schön, 1974, 1978, 1996) becomes essential in control-meritocratic organizations. In double loop learning individuals, groups or organizations also correct or change the underlying causes behind any 
procedure or task. So, norms, policies, ways to work, rules, and assumptions are questioned. It is about changing the rules. Double loop learning forces us to think on our goals, policies or operating assumptions. It occurs when errors are detected and corrected such that existing policies, goals, and assumptions are called into question and challenged.

Control meritocratic organizations focus on the future, on the things they want or they need to do. So, achievement is an important concept. Change and innovation are an opportunity, and are also seen as essential.

Standardization of outputs (Mintzberg, 1985), which achieves coordination by specifying the results of different work, would be the most important coordinating mechanism, which relates this organization to Minztberg's diversified configuration. Management by objectives or by results (Drucker, 1954) or the process of defining specific objectives within an organization that management can convey to organization members is spread over these organizations. So, indicators, goals, strategies, strategic planning are king.

Power is vested in individuals that achieve certain goals or have certain merits. Meritocracy, and incentive systems turn out essential. So, more is always better, according to this level of consciousness, which brings about overconsumption, corporate greed and materialism. On the other hand, management must solve only tangible problems, putting tasks over relationships. They are transactional leaders that value dispassionate rationality, and are wary of emotions.

\section{The commitment organization}

This level of consciousness considers that there is more to life than success or failure, taking into account the dark side of the previous level: the materialistic obsession, the social inequality and the loss of community (Cowan and Todorovic, 2000; Cacioppe and Edwards, 2004; Laloux, 2014). The green pluralistic level of consciousness is highly sensitive to people's feelings, fairness, equality, cooperation, learning and consensus. According to Laloux (2014), one of the main characteristics of this organization is the concept of belonging. Charismatic or transformational leaders play an essential role in it. 
Besides, the commitment organization stresses the importance of bottom-up processes, gathering input from all and trying to bring opposing points of view to eventual consensus. Empowerment and decentralization are spread over the organization. The commitment organization aims at getting more from workers by giving more to them (Baron and Kreps, 1999, p. 189).

Rules in this organization tend to be social, based on the social control or culture. Culture is paramount in this organization, where values, and cultural aspects are taking into account. Consequently, standardization of skills and (cultural) norms are the most important coordinating mechanism, which might imply that it is related to Mintzberg's (1985) professional and missionary configuration.

Therefore, the aim of this organization is to develop a context, a culture where cooperation, equality, consensus or learning takes place. This is why deutero learning (Argyris and Schön, 1974, 1978, 1996) or meta-learning (Visser, 2007), implying learning how to carry out single and double loop learning becomes important. Learning to learn, to cooperate, to empower, or to act with fairness might be some of the examples.

Deutero learning (Argyris and Schön, 1974,1978, 1996) or meta-learning (Visser, 2007) imply to reflect on and inquire into the process in which single and double loop learning are taking place. Reflecting on the process of single-loop learning implies thinking about ways to improve error detection and correction, and thus to improve the effectiveness of action strategies (Visser, 2007). Reflecting on the process of double loop learning involves thinking about ways to improve discussion about norms and values underlying action strategies (Visser, 2007).

\section{The learning organization}

The last level of consciousness happens when one learns to disidentify from one's own ego. By looking at it from a distance, one can see how its fears, ambitions, and desires run one's life (Cowan and Todorovic, 2000; Cacioppe and Edwards, 2004; Laloux, 2014). Laloux (2014) considers that when we are fused with our ego, we are driven to make decisions informed by external factors, like goals, social norms, authority etc. In this level, we shift from external to internal yardsticks in our decision-making. So, we are concerned with inner rightness. Some examples of the questions that arise are (Laloux, 2014): does this decision seem right? Am I being true to myself? Is this in line 
with who I sense I am called to become? Am I being of service to the world? Laloux (2014) considers that in this level the ultimate goal in life is to become the truest expression of ourselves, to live into authentic selfhood, which can be strongly related to the Senge's (1990) discipline of personal mastery, which is one of his requirements to achieve a learning organization.

Mutual adjustment (1985), which achieves coordination by the simple process of informal communication, could be considered as the most important coordinating mechanism of the learning organization. It could be then related to Mintzberg's (1985) adhocracy, which is a flexible, adaptable and informal form of organization that is defined by a lack of formal structure, or Robertson's (2015) Holacracy, which is a flat organization based on self-management teams. So, peer relationships are essential, beyond hierarchy or consensus. These organizations are characterized by:

- Existence of no status symbols which implies no bosses or subordinates. They are simply members of the organization.

- Due to trust in people, employees do not need to sign in or out.

- There aren't functional departments, especially of innovation and human resource management. All assumes those functions.

- There tend to be long lasting relationships with customers and suppliers.

- People work on whatever they want and whom they want with.

- People can experiment and try new things easily, as they are not afraid of making mistakes.

- Transparency is a must in these organizations. All information is available.

- People assume roles instead of Jobs or job titles. This fosters flexibility.

- Coordination and meetings happen when needs arise. Coordination usually comes informally.

- Teams and teamwork are essential. In fact, these organizations tend to focus on team performance.

- Anyone can make decisions on any matter, but it is highly recommended to ask for advice.

- There are usually rotation programs to immerse new members in the organization

- As conflicts are usual in these organizations, they usually propose multi-step conflict resolution procedures. 
- These organizations tend to be self-decorated, warm spaces, open to children and pets. Meditation and quiet spaces are in most of the learning organizations.

- Emotions become paramount in these organizations. Intuition -and not rationality- is king. Intuition honours the complex, ambiguous, paradoxical, nonlinear nature of reality. We unconsciously connect patterns in a way that our rational mind cannot. These organizations foster to go beyond "the professional" self by stressing the importance of emotions, personal life, spirituality, intuition, doubts, etc.

- Change is no longer a relevant topic, because learning organizations adapt and learn constantly.

- Members are invited to participate in inquiring about the organization's evolution, purpose, values and basic intrinsic hypothesis, which is strongly related to triple loop learning (Swieringa and Wierdsma, 1992; Tosey et al., 2011).

Triple loop learning (Swieringa and Wierdsma, 1992; Nielsen, 1993; Tosey et al., 2011) happens when the essential principles on which the organization is founded come into discussion, involving the development of new principles, with which the organization can proceed to a subsequent phase. This level of learning is considered as superior to single and double loop learning, and implies questioning the underlying paradigms, purposes, essential principles, whatever governs those governing variables, the role, or the mission of the organization.

\section{Discussion and conclusion}

This theoretical paper aims to describe the learning organization in relationship with other types of organizations. This typology is based on the levels of consciousness (Gebser, 1949; Graves, 1970; Beck and Cowan, 1996; Wilber, 2000; Laloux, 2014), and relates each type of organization with a level of learning (Bateson, 1972; Argyris and Schön, 1974, 1978, 1996; Visser, 1997; Swiering and Wierdsma, 1992; Tosey et al., 2011) and an organizational structure (Mintzberg, 1989).

In so doing, the paper claims that the learning organization is related to the highest level of consciousness, as it is considered to have all the levels of learning (Örtenblad, 2004) and to have most of the managerial and organizational characteristics described in the previous section. Consequently, to develop such an organization a "teal" level of consciousness is required. So, this paper claims that any organization can become a 
learning organization as long as it has a common welfare and holistic (teal) level of consciousness. So, if an organization and its members share an achievement and autonomy level of consciousness (orange) and aim to become a learning organization, and only focus in certain contextual characteristics, they will not be able to actually attain it, as long as they keep on following an orange level of consciousness. Although it would be quite advisable and good for our society that most organizations become learning organizations, it seems to be quite unlikely that the highest level of consciousness is the most important one in our business world, as least so far.

On the other side, the paper does not claim that to become a learning organization is the only way to be successful, as the concept of success will depend on the level of consciousness of the organization.

Furthermore, although this paper summarizes some of the most conspicuous characteristics of the learning organization, they can have specific or particular characteristics. Not all learning organizations have the same characteristics (Örtenblad, 2015); however, the paper claims that learning organizations all require the highest level of consciousness.

Future research should aim to test and deepen into the ideas claimed in this paper about learning organizations, and also into the relationship between the teal level of consciousness, the existence of triple loop learning and an adhocratic or holocratic structure.

\section{References}

Argyris, C. and Schön, D. (1974), Theory in Practice: Increasing Professional Effectiveness, Jossey-Bass, San Francisco, CA.

Argyris, C. and Schön, D. (1978), Organizational Learning: A Theory of Action Perspective, McGraw-Hill, New York, NY.

Argyris, C. and Schön, D. (1996), Organizational Learning II: Theory, Method and Practice, Addison-Wesley, Reading. MA.

Bateson, G. (1972), Steps to an Ecology of Mind, Ballantine, New York, NY.

Beck, D. and Cowan, C. (1996), Spiral Dynamics: Mastering Values, Leadership, and Change, Blackwell Publishers, Malden, MA.

Burgoyne, J. (1999), "Design of the times”, People Management, Vol. 5 No. 11, pp. 3844. 
Cacioppe, R. and Edwards, M.G. (2005), "Seeking the holy grail of organizational development: a synthesis of integral theory, spiral dynamics, corporate transformation and developmental action inquiry", Leadership and Organizational Development Journal, Vol. 26 No. 2, pp. 86-105.

Chiva, R. (2014), "The common welfare human resource management system”, Personnel Review, Vol. 43 No. 6, pp. 937-956.

Chiva, R. and Alegre, J. (2009), "Organizational learning capability and job satisfaction: an empirical assessment in the ceramic tile industry", British Journal of Management, Vol. 20 No. 3, pp. 323-340.

Cowan, C.C. and Todorovic, N. (2000), "Spiral dynamics: the layers of human values in strategy", Strategy \& Leadership, Vol. 28 No. 1, pp. 4-12.

Drucker, P. (1954), The Practice of Management, Harper and Row, New York, NY.

Garrat, B. (1987), The Learning Organization, Harper Collins, London, UK.

Gebser, J. (1949), The Ever-Present Origin, Ohio University Press, Athens, OH.

Graves, C.W. (1970), "Levels of existence: an open system theory of values", The Journal of Humanistic Psychology, Vol. 10 No. 2, pp. 131-154.

Laloux, F. (2014), Reinventing Organizations: A Guide to Creating Organizations Inspired by the Next Stage in Human Consciousness, Nelson Parker, Brussels, Belgium.

Mintzberg, H. (1989) Mintzberg on Management. The Free Press: NY, New York.

Örtenblad, A. (2004), "The learning organization: towards an integrated model", The Learning Organization, Vol. 11 No. 2, 129-144.

Örtenblad, A. (2015), "Towards increased relevance: Context-adapted models of the learning organization”, The Learning Organization, 22(3), 163-181

Pedler, M., Burgoyne, J. and Boydell, T. (1991), The Learning Company: A Strategy for Sustainable Development, McGraw-Hill, London, UK.

Robertson, B. (2015), Holacracy: The New Management System for a Rapidly Changing World, Henry Holt and Co, New York, NY.

Senge, P. (1990), The Fifth Discipline: The Art and Practice of the Learning Organization, Doubleday, New York, NY.

Swieringa, J. and Wierdsma, A. (1992), Becoming a Learning Organization: Beyond the Learning Curve, Addison-Wesley, Wokingham, UK.

Tosey, P.C., Visser, M. and Saunders, M.N.K. (2012), "The origins and conceptualisations of 'triple-loop' learning: a critical review", Management Learning, Vol. 43 No. 3, pp. 289-305.

Tsang, E.W.K. (1997), "Organizational learning and the learning organization: a dichotomy between descriptive and prescriptive research", Human Relations, Vol. 50 No. 1 , pp. 73-89. 
Ulrich, D., Jick, T. and von Glinow, M.A. (1993), "High-impact learning: building and diffusing learning capability", Organizational Dynamics, Vol. 22 No. 2, pp. 52-66.

Visser, M. (2003), "Gregory Bateson on deutero-learning and double bind: a brief conceptual history", Journal of the History of the Behavioral Sciences, Vol. 39 No. 3, pp. 269-278.

Visser, M. (2007), "Deutero-learning in organizations: a review and reformulation", Academy of Management Review, Vol. 32 No. 2, pp. 659-667.

Watkins, K.E. and Golembiewski, R.T. (1995), "Rethinking organization development for the learning organization", The International Journal of Organizational Analysis, Vol. 3 No. 1, pp. 86-101.

Wilber, K. (2000). A Theory of Everything: An Integral Vision for Business, Politics, Science and Spirituality, Shambala Publications, Boston, MA. 